\title{
The use of photographic rates to estimate densities of tigers and other cryptic mammals
}

C. Carbone ${ }^{1}$, S. Christie ${ }^{2}$, K. Conforti ${ }^{3}$, T. Coulson ${ }^{1 *}$, N. Franklinn ${ }^{4,5}$, J. R. Ginsberg ${ }^{6}$, M. Griffiths ${ }^{7}$, J. Holden $^{8}$, K. Kawanishi ${ }^{9}$, M. Kinnaird ${ }^{6}$, R. Laidlaw 6 , A. Lynam ${ }^{6}$, D. W. Macdonald ${ }^{10}$, D. Martyr ${ }^{8}$, C. McDougal ${ }^{11}$, L. Nath ${ }^{10}$, T. O’Brien ${ }^{6}$, J. Seidensticker ${ }^{3}$, D. J. L. Smith ${ }^{12}$, M. Sunquist ${ }^{9}$, R. Tilson ${ }^{5}$ and W. N. Wan Shahruddin ${ }^{6}$

Authorship in alphabetical order

${ }^{1}$ Institute of Zoology, Zoological Society of London, Regent's Park, London NW1 4RY, UK

${ }^{2}$ London Zoo, Zoological Society of London, Regent's Park, London NW1 4RY, UK

${ }^{3}$ Smithsonian National Zoological Park, Washington DC 2008, USA

${ }^{4}$ Department of Biology, University of York, York YO1 5DD, UK

${ }^{5}$ Sumatran Tiger Project, PO Box 190, Metro, Lampung 34101, Sumatra, Indonesia

${ }^{6}$ Wildlife Conservation Society, International Programs, 2300 Southern Boulevard, Bronx, New York, NY 10460-1099, USA

${ }^{7}$ Leuser Development Programme, Jl. Dr. Mansyur 68, Medan 20154, Sumatra, Indonesia

${ }^{8}$ Fauna and Flora International, Great Eastern House, Tenison Road, Cambridge CB1 2DT, UK

${ }^{9}$ Department of Wildlife Ecology and Conservation, University of Florida, PO Box 110430, Gainesville, FL, USA

${ }^{10}$ Wildlife Conservation Research Unit, Department of Zoology, University of Oxford, South Parks Road, Oxford, OX1 3PS, UK

${ }^{11}$ Tiger Tops, PO Box 242, Kathmandu, Nepal

${ }^{12}$ Dept of Fisheries and Wildlife, 200 Hodson Hall, 1980 Folwell Avenue, St Paul, MN 55108, USA

(Received 4 May 2000; accepted 14 September 2000)

\begin{abstract}
The monitoring and management of species depends on reliable population estimates, and this can be both difficult and very costly for cryptic large vertebrates that live in forested habitats. Recently developed camera trapping techniques have already been shown to be an effective means of making mark-recapture estimates of individually identifiable animals (e.g. tigers). Camera traps also provide a new method for surveying animal abundance. Through computer simulations, and an analysis of the rates of camera trap capture from 19 studies of tigers across the species' range, we show that the number of camera days/tiger photograph correlates with independent estimates of tiger density. This statistic does not rely on individual identity and is particularly useful for estimating the population density of species that are not individually identifiable. Finally, we used the comparison between observed trapping rates and the computer simulations to estimate the minimum effort required to determine that tigers, or other species, do not exist in an area, a measure that is critical for conservation planning.
\end{abstract}

\section{INTRODUCTION}

Since their development in the early 1980s camera traps have become an important tool for monitoring rare, cryptic species in a wide range of environments (Champion, 1992; Griffiths \& van Schaik, 1993; Karanth \& Nichols, 1998; Cutler \& Swann, 1999). This technique is used for species that can be individually identified to assess population size, population turnover rates and many aspects of species ecology (Karanth \& Nichols, 1998) . However, in most camera trapping programmes individually marked target species represent only a fraction of the total species assemblage (e.g. tiger pho-

All correspondence to: Dr C. Carbone, Institute of Zoology,

Zoological Society of London, Regent's Park, London, NW1 4RY.

Tel: 0207449 6634; Fax: 0207483 2237;

E-mail: chris.carbone@ioz.ac.uk. tographs represented $5 \%$ of the total number of photographs taken in one study (N. Franklin \& R. Tilson, unpubl. results). A technique that could use photographic rates of non-identifiable individuals to estimate animal density would greatly increase the use of these data. In this paper, we compare the observed relationship between photographic rates of tigers and their density with the results of a random walk simulation of a twodimensional gas model (Lowen \& Dunbar, 1994) in order to assess the ability of camera trapping programmes to estimate animal densities and detect animals at low densities.

\footnotetext{
*Current address: Large Animal Research Group, Department of Zoology, University of Cambridge, Downing Street, Cambridge.
} 


\section{METHODS}

\section{Camera trapping data}

Camera trapping data were obtained from studies in India, Nepal, Thailand, Malaysia and Indonesia (Table 1). Photographic rate was defined as the number of camera days $(24 \mathrm{~h})$ per tiger ( $\geq 1$ year old) photograph summed across all camera traps in the study (see Table 1). Tiger density (expressed as the number of tigers $/ 100 \mathrm{~km}^{2}$ ) was estimated from the number of individually identified tigers photographed divided by the estimated sampling area of the study.

Previous studies have used a more robust measure of population size based on a mark-recapture method (Karanth \& Nichols, 1998). These estimates were not available for most of the studies used in this analysis. However, in five studies, where both mark-recapture and total number identified estimates were available, these were strongly correlated (see e.g. Table 3 in Karanth \& Nichols, 1998). In addition, tigers were typically photographed five times over the course of the study and it seems reasonable to assume therefore that most of the population had been identified. We feel justified, therefore, in using estimates based on the total number identified for all of the 19 studies. In 15 studies, sampling area was estimated as the area covered by the traps plus an additional boundary layer estimated from tiger movement distance (see Table 1). In the remaining four studies, information on the movement patterns of tigers and park boundaries was used to estimate sample area. Excluding these four studies did not significantly alter the results (see below).

\section{Random walk simulation}

The observed relationship between photographic rates and density was compared with the relationship obtained from a random walk simulation. We did not expect a simple random walk model to represent the complexities of tiger ranging patterns, but we used the model to interpret the observed data more generally. The simulations were based on a circular field of $10000 \mathrm{~km}^{2}$ and

Table 1. Data obtained from 19 studies, based in five countries

\begin{tabular}{|c|c|c|c|c|c|c|c|c|}
\hline Location & Country & Source & $\begin{array}{l}\text { Total } \\
\text { camera } \\
\text { days } \\
(24 \mathrm{~h})\end{array}$ & $\begin{array}{l}\text { Total no. } \\
\text { photos }\end{array}$ & $\begin{array}{l}\text { Total no. } \\
\text { tigers } \\
(\geq 1 \mathrm{yr})\end{array}$ & $\begin{array}{l}\text { Sampling } \\
\text { area } \\
\left(\mathrm{km}^{2}\right)\end{array}$ & $\begin{array}{l}\text { Tiger } \\
\text { density } \\
\text { (no./ } \\
100 \mathrm{~km}^{2} \text { ) }\end{array}$ & $\begin{array}{l}\text { Number } \\
\text { of } \\
\text { days/tiger } \\
\text { photo }\end{array}$ \\
\hline Kanha & India & U. Karanth pers. comm. & $937.1^{1}$ & 87 & 26 & $282^{2}$ & 9.22 & 10.8 \\
\hline Kaziranga & India & U. Karanth pers. comm. & $644.2^{1}$ & 80 & 22 & $167^{2}$ & 13.17 & 8.1 \\
\hline Nagarahole & India & U. Karanth pers. comm. & $1092.3^{1}$ & 76 & 25 & $243.4^{2}$ & 10.27 & 14.4 \\
\hline Pench & India & U. Karanth pers. comm. & $919.6^{1}$ & 42 & 5 & $121.6^{2}$ & 4.11 & 21.9 \\
\hline Bandhavgarh, India & India & L. Nath (unpubl. data) & $357.2^{1}$ & 106 & 15 & $105^{3}$ & 14.29 & 3.4 \\
\hline $\begin{array}{l}\text { Way Kambas } \\
\text { (annual average) }\end{array}$ & Indonesia & $\begin{array}{l}\text { N. Franklin \& R. Tilson } \\
\text { (unpubl. data) }\end{array}$ & 5030 & 126 & 18 & $350^{2}$ & 5.14 & 39.9 \\
\hline Gunung Leuser & Indonesia & Griffiths (1994) & 2686 & 45 & 10 & $550^{3}$ & 1.82 & 59.7 \\
\hline Bukit Barisan Selatan & Indonesia & $\begin{array}{l}\text { T. O'Brian \& M. Kinnaird } \\
\text { (unpubl. data) }\end{array}$ & 4064 & 19 & 9 & $836^{2}$ & 1.08 & 213.9 \\
\hline Kerinchi Seblat & Indonesia & $\begin{array}{l}\text { D. Martyr \& J. Holden } \\
\text { (unpubl. data) }\end{array}$ & 5316 & $62^{3}$ & 16 & $800^{3}$ & 2.00 & 85.7 \\
\hline Chitwan (1996-97) & Nepal & $\begin{array}{l}\text { C. McDougal et al. } \\
\text { (unpubl. data) }\end{array}$ & $561^{1}$ & 120 & 25.5 & $161^{3}$ & 15.84 & 4.7 \\
\hline $\begin{array}{l}\text { Halabala Wildlife } \\
\text { Sanctuary, Narathiwat } \\
\text { Province }\end{array}$ & Thailand & A. Lynam (unpubl. data) & 999 & $9^{2}$ & 2 & $166.7^{2}$ & 1.20 & 111.0 \\
\hline $\begin{array}{l}\text { Queen Sirikit Reserve } \\
\text { Forest, Yala Province }\end{array}$ & Thailand & A. Lynam (unpubl. data) & 683 & $17^{2}$ & 3 & $166.7^{2}$ & 1.80 & 40.2 \\
\hline $\begin{array}{l}\text { Phu Khieo Wildlife } \\
\text { Sanctuary, Chaiyaphum } \\
\text { Province }\end{array}$ & Thailand & A. Lynam (unpubl. data) & 989 & $3^{2}$ & 1 & $86.2^{2}$ & 1.16 & 329.7 \\
\hline $\begin{array}{l}\text { Khao Yai National } \\
\text { Park, Nakhon } \\
\text { Ratchasima Province }\end{array}$ & Thailand & A. Lynam (unpubl. data) & 647 & $2^{2}$ & 1 & $83.3^{2}$ & 1.20 & 323.5 \\
\hline $\begin{array}{l}\text { Temenggor Forest } \\
\text { Reserve, Perak }\end{array}$ & Malaysia & $\begin{array}{l}\text { R. Laidlaw \& Wan } \\
\text { Shahruddin (unpubl. data) }\end{array}$ & 812 & $8^{2}$ & 2 & $86.2^{2}$ & 2.32 & 101.5 \\
\hline $\begin{array}{l}\text { Bintang Hijau Forest } \\
\text { Reserve, Perak }\end{array}$ & Malaysia & $\begin{array}{l}\text { R. Laidlaw \& Wan } \\
\text { Shahruddin (unpubl. data) }\end{array}$ & 776 & $7^{2}$ & 2 & $202.0^{2}$ & 0.99 & 110.9 \\
\hline $\begin{array}{l}\text { Gunung Tebu Forest } \\
\text { Reserve, Terngganu9 }\end{array}$ & Malaysia & $\begin{array}{l}\text { R. Laidlaw \& Wan } \\
\text { Shahruddin (unpubl. data) }\end{array}$ & 807 & 12 & 1 & $188.7^{2}$ & 0.53 & 67.3 \\
\hline $\begin{array}{l}\text { Ulu Temaing Forest } \\
\text { Reserve, Kelantan }\end{array}$ & Malaysia & $\begin{array}{l}\text { R. Laidlaw \& Wan } \\
\text { Shahruddin (unpubl. data) }\end{array}$ & 563 & 15 & 2 & $210.5^{2}$ & 0.95 & 37.5 \\
\hline Taman Negara & Malaysia & $\begin{array}{l}\text { K. Kawanishi \& M. } \\
\text { Sunquist (unpubl. data) }\end{array}$ & $1829^{1}$ & 6 & 4 & $338.2^{2}$ & 1.18 & 304.8 \\
\hline
\end{tabular}

Mean tiger densities represent the total number of tigers ( $\geq 1$ year) identified over the course of the study, divided by the sampling area. Camera photographic rate was calculated from the total number of days the cameras were active divided by the total number of tiger photographs obtained (discarding duplicates of the same individual during one visit to the trap).

${ }^{1}$ Camera traps were run on a $14-16 \mathrm{~h} /$ day schedule and these rates were converted to a $24 \mathrm{~h} /$ day rate.

${ }^{2}$ Sampling area was based on the area covered by the camera traps, which included a boundary layer estimated using half of the mean maximum distance travelled by tigers within the study area (see Karanth \& Nichols, 1998).

${ }^{3}$ Sampling area based on tiger home ranges and park boundaries. 
simulated tiger density was varied within this field from $0.5 / 100 \mathrm{~km}^{2}$ to $100 / 100 \mathrm{~km}^{2}$. One camera trap was located in the centre. Each day the tigers moved to a new position by randomly assigning a straight-line distance with a mean of either 3,10 or $40 \mathrm{~km}$ (standard deviation of 1.0). The lower two values of daily distance were chosen to approximate observed total daily distances estimated for tigers (including deviations from the straight line distance). For example, in the Russian Far East one male and one female averaged a total distance of $9.6 \mathrm{~km}$ and $7 \mathrm{~km} /$ day, respectively, between kills (Yudakov \& Nikolaev, 1987). This represents an upper limit because tigers typically remain near each kill for a day or more. In India, males and females moved on average 4.2 and $1.4 \mathrm{~km} /$ day (estimated straight line distance, Chundawat, Gogate \& Johnsingh, 1999). The simulations based on a daily distance of $40 \mathrm{~km}$ provided capture rates that were close to the observed capture rates (see below) and these were carried out to illustrate the sensitivity of the model predictions to travel distance. The simulated daily distance was varied according to a normal distribution with a standard deviation of 1.0 and negative values converted to zeros. Tiger movements were restricted to the area of the field and positions that fell outside this area were re-selected. When the tiger's start or end positions, or the line of travel between positions, fell within the radius of detection $(4 \mathrm{~m})$ of the camera trap, a photograph was recorded. These photos were summed over 1000 days for each density and daily range. We also examined the proportion (number out of 100 runs) of camera trapping programmes (1000 camera trap days each) that were successful at obtaining one or more photographs at low simulated animal densities.

\section{Comparing observed data and simulated data}

Nineteen values were randomly selected from each set of simulated data (3, 10 and $40 \mathrm{~km}$ moved/day). The slopes and intercepts between the observed and simulated data were compared ( $y=$ trap days/photograph, $x=$ number of tigers $/ 100 \mathrm{~km}^{2}$ ). This was done in a general linear model with a normal error structure with simulation/observation fitted as a factor. A significant interaction term between the effects of density (continuous variable) and the simulation/observation factor would highlight a significance difference between slopes. There was no significant difference between slopes and we dropped the simulation/observation factor from the final model (see Results, below).

\section{RESULTS}

Across 19 field studies, there was a significant relationship between photographic rates of tigers (number of camera days/tiger photograph) and tiger density (tigers $\left./ 100 \mathrm{~km}^{2}\right) ; y=140.33 x^{-1.116} ; \mathrm{F}_{(1,17)}=47.43 ; r^{2}=$ $0.72 .1 ; P<0.001$; (Fig. 1(a)). Removing the four studies that used park boundaries to estimate sampling area did not alter this result substantially; $y=133.89 x^{-0.971}$; $\mathrm{F}_{(1,13)}=21.12 ; r^{2}=0.61 .9 ; P<0.002$; (Fig. 1(a)). The slope and form of the function estimated from the observed results was very similar to the relationship achieved from a random walk simulation (daily distance $=3 \mathrm{~km}$, power curve regression, $y=2866.4 x^{-0.957} ; r^{2}=$ 0.81 ; daily distance $=10 \mathrm{~km}$, power curve regression, $y=703.1 x^{-0.938} ; r^{2}=0.96$ ) (Fig. 1(b)). These relationships differ significantly in intercept but not in slope; $\mathrm{F}_{(4,71)}=1.43, P=0.242$. Dropping the simulation/observation factor from the model we got: $\mathrm{F}_{(3,74)}=117.77, P$ $<0.001$. This suggested that photographic rates are associated with tiger densities in a way that reflects a random process, but that the observed photographic rates were much higher than expected from the random walk model at equivalent densities. Two factors may be contributing to the differences between the model and the observed relationships. Firstly, tigers may use only a fraction of the total area inside their home range (e.g. Miquelle et al., 1999); and/or tigers move much greater distances than we assume. A mean daily distance of 40 $\mathrm{km}$ was needed to produce photographic rates similar to the observed rates $\left(y=146.8 x^{-1.03} ; r^{2}=0.96\right)$ (Fig. 1(b)) and this represents an unrealistically high long term average travel distance for this species. It seems reasonable to assume therefore, that the differences between the predicted and observed photographic rates reflect the fact that camera traps are placed in areas where tigers and other large mammals are known to occur.

We used the ratio of the regression constants in the predicted and observed equations (predicted/observed) to provide a correction factor between the simulated and observed capture rates (i.e. 2886.4/143.9 = 19.9 and $703.1 / 143.9=4.9$ (average of 12.4 ) for $3 \mathrm{~km}$ and $10 \mathrm{~km}$, respectively). With these correction factors, we could use the model simulation to interpret the performance of camera trapping programmes at very low 'animal' densities. Our random walk model predicted that programmes running for 1000 camera days had a $95 \%$ chance of obtaining at least one photograph at simulated animal densities of between roughly two and five individuals $/ 100 \mathrm{~km}^{2}$, assuming even use of the habitat (Fig. 2). If we applied the same correction factors estimated above for the two sets of simulations (19.9 for 3 $\mathrm{km}$ and 4.5 for $10 \mathrm{~km}$ ) this would correspond to tiger densities of between 0.38 and $0.71 / 100 \mathrm{~km}^{2}$. If we increased the trapping effort to 10000 trap days, we predicted that tiger presence could be determined with the same confidence level down to a density of $0.05 / 100 \mathrm{~km}^{2}$.

\section{DISCUSSION}

Overall there is a good correlation between the photographic rate measured in terms of days per tiger photograph and tiger density. The relationship holds despite variations in methodology and terrain among field sites, indicating that estimates of average photographic rates of unknown individuals may provide a robust measure of tiger densities. The fact that the observed relationship scales similarly to the simple random walk model suggests that, on average, tiger movements are evenly 


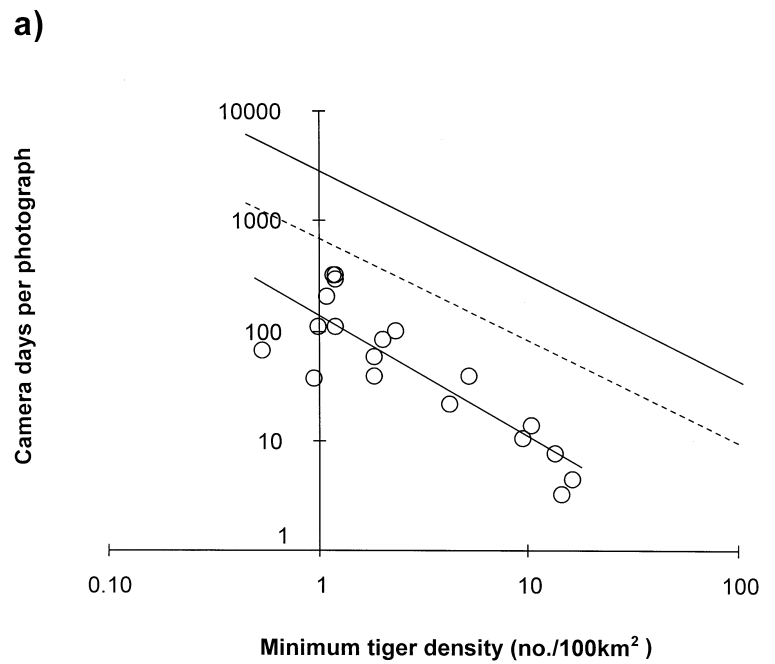

b)

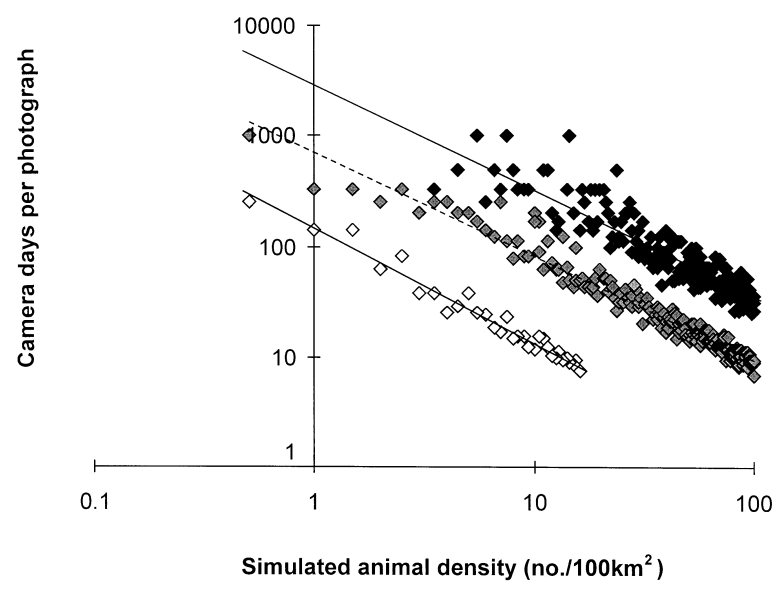

Fig. 1. (a) The number of camera days/tiger photograph plotted against estimated tiger density (see Methods for details). Each point represents the mean tiger density and photographic rates outlined in Table 1 . The top two lines represent the regression lines for the simulated data illustrated in Fig. 1(b) ( $3 \mathrm{~km}$, top continuous line; $10 \mathrm{~km}$, bottom dashed line). The bottom line is the regression line for the camera trap data (this regression line is also plotted with the $40 \mathrm{~km}$ per day (open diamonds) simulated data in Fig. 1(b). Simulated capture rates for animal densities of $0.5-100 / \mathrm{km}^{2}$ assuming a mean daily distance of $3 \mathrm{~km}$ (filled diamonds), $10 \mathrm{~km}$ (grey diamonds) and $40 \mathrm{~km}$ (open diamonds). The simulations based on a daily distance of $40 \mathrm{~km}$ were made to provide capture rates that were near the observed rates. Each point represents the means from 1000 camera trapping days. The slopes of the simulated data do not differ significantly from the observed relationship (see Fig. 1(a) and see the text for details).

distributed over a fraction of the total home range area. This is not surprising. We know that although the camera location on a large scale may be chosen to meet specific statistical objectives, on a local scale sites are chosen in order to maximize encounter rates (Karanth, 1999). This is done by placing cameras in locations close to tiger markings or on trails, roads and ridges that represent routes of travel for many species.

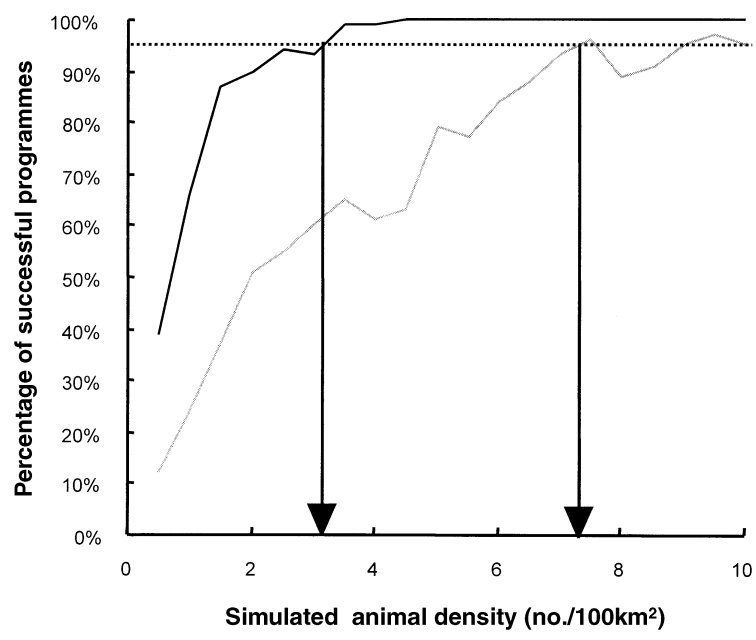

Fig. 2. The $\%$ of simulated camera trapping programmes (number out of 100 runs, 1000 camera days each) that obtained at least one photograph against animal density $\left(N / 100 \mathrm{~km}^{2}\right)$ assuming a daily travel distance of $3 \mathrm{~km}$ (grey line) and $10 \mathrm{~km}$ (black line). The vertical arrows represent the approximate density at which there is a $95 \%$ chance of obtaining one photograph. The mean number of days per photograph at these densities is 391.8 and 246.3 days (for daily travel distances of $3 \mathrm{~km}$ and $10 \mathrm{~km}$ respectively). The corresponding tiger densities based on the ratio of the simulated and observed capture rates would be approximately 0.4 and 0.7 tigers $/ 100 \mathrm{~km}^{2}$ (see text for details).

Because the statistic used does not rely on individual identity, the method can, in principle, be used on a wide range of species. For studies on tigers, camera traps are typically distributed over an area of between 150 and $350 \mathrm{~km}^{2}$ (Table 1) and the cameras may be several $\mathrm{km}$ apart. Based on our results and the camera distributions used for tigers, we expect that this technique would be most effective for species that are relatively wide ranging, ( $\geq 1 \mathrm{~km} /$ day), with a minimum animal density of two or more per $100 \mathrm{~km}^{2}$ (Fig. 1(a)) and which are solitary or found in very small groups. Many large forest dwelling mammals meet such conditions. In addition, many of these species will be found at far higher densities than the tiger densities used in this study and this should lead to a reduction in the variation in the photographic rate index. Given that only a small fraction of the species photographed by camera traps are individually identifiable, this technique could greatly increase the use of camera trap data for estimating large mammal abundance. However, the effective use of this technique will depend on our ability to obtain independent estimates of animal density at representative sites in combination with camera-trapping data in order to calibrate the photographic rates (e.g. T. O'Brien \& M. Kinnaird, unpubl. data).

Systematic sampling of tiger populations through the use of mark-recapture will usually give a more accurate estimate of tiger population number. This method also allows a measurement error to be estimated for a particular site and can be used in areas with both high and low densities of animals (K. U. Karanth, pers com; 
Karanth \& Nichols, 1998). Thus, we would recommend that, where possible, scientists design sampling protocols that use mark-recapture methods to estimate animal population densities. The method described in this paper is clearly appropriate for rapid assessments, and is critical in developing methods to estimate the density of animals other than tigers which cannot be individually identified from their markings.

Finally, by comparing observed trapping rates with the results of our computer simulations, we were able to calculate the sampling effort required to determine whether tigers were present in an area. Our analysis suggested that camera trapping programmes (running for 1000 or more camera days) may be successful in estimating presence or absence of tigers in densely forested habitats at very low densities $\left(0.4\right.$ to 0.7 tigers $\left./ 100 \mathrm{~km}^{2}\right)$. By increasing the trapping effort to 10000 trap days we predict that tiger presence could be detected down to a density of 0.05 tigers $/ 100 \mathrm{~km}^{2}$.

This research has important implications for the conservation of tigers and other large carnivores. The tiger is a habitat generalist ranging across 14 countries. Like many large carnivores, its distribution and population viability is linked with the distribution and abundance of large prey (Carbone et al., 1999; Karanth \& Stith, 1999). The amount of potential habitat that is actually occupied by tigers is unknown, and nearly all potential and occupied tiger habitat, including protected areas, is undergoing substantial change (Dinerstain et al., 1997). With the procedures we describe here we have, for the first time, a rapid, quantifiable, non-invasive means to assess both tiger and prey numbers and identify landscape patterns and conditions that determine the distribution of viable tiger populations.

\section{Acknowledgements}

We thank Ullas Karanth, Jim Nichols and Georgina Mace for comments on earlier drafts of the manuscript. Funding sources for the 19 tiger studies included the Save The Tiger Fund, Esso UK plc, the Tiger Foundation, the Zoological Society of London, the Wildlife Conservation Society, Disney Wildlife Conservation Fund, University of Florida, WWF-Japan, WWF-UK, WWF-Netherlands, SFWS, Care for the Rare program of Justerini \& Brooks Ltd. and the International Trust for Nature Conservation.

\section{REFERENCES}

Carbone, C., Mace, G., Roberts, S. C. \& MacDonald, D. W. (1999). Energetic constraints on the diet of terrestrial carnivores. Nature 402: 286-288.

Champion, F. W. (1992). With a camera in tiger-land. London: Catto \& Windus.

Chundawat, R., Gogate, N. \& Johnsingh, A. J. T. (1999). Tigers in Panna: preliminary results from an Indian tropical dry forest. In Riding the tiger: Tiger conservation in human-dominated landscapes: 123-129. Seidensticker, J., Christie, S. \& Jackson, P. (Eds).Cambridge: Cambridge University Press.

Cutler, T. L. \& Swann, D. E. (1999). Using remote photography in wildlife ecology: a review. Wildl. Soc. Bull. 27: 571-581.

Dinerstein, E., Wikramanayake, E., Robinson, J., Karanth, U., Rabinowitz, A., Olson, D., Mathew, T., Hedao, P., Connor, M., Hemley, G. \& Bolze, D. (1997). A framework for identifying high priority areas and actions for the conservation of tigers in the wild. Part 1. Washington DC: World Wildlife Fund, USA and Wildlife Conservation Society.

Griffiths, M. G. (1994). Population density of Sumatran tigers in Gunung Leuser National Park. In Sumatran Tiger Population and Habitat Viability Analysis Report, ed. R. Tilson, K. Soemarna, W. Ramono, S. Lusli, K. Traylor-Holzer \& U. Seal, pp. 93-102. Apple Valley, Minnesota, Indonesian Directorate of Forest Protection and Nature Conservation and IUCN/SSC Conservation Breeding Specialist Group.

Griffiths, M. G. \& van Schaik, C. P. (1993) Camera-trapping: a new tool for the study of elusive rain forest animals. Trop. Biodiv. 1: 131-135.

Karanth, K. U. (1999). Counting tigers, with confidence. In Riding the tiger: Tiger conservation in human-dominated landscapes: 350-353. Seidensticker, J., Christie, S. \& Jackson, P. (Eds). Cambridge: Cambridge University Press.

Karanth, K. U. \& Nichols, J. D. (1998). Estimation of tiger densities in India using photographic captures and recaptures. Ecology 79: 2852-2862.

Karanth, K. U. \& Stith, B. M. (1999). Prey depletion as a critical determinant of tiger population viability. In Riding the tiger: Tiger conservation in human-dominated landscapes: 100-113. Seidensticker, J., Christie, S. \& Jackson, P. (Eds). Cambridge: Cambridge University Press

Lowen, C. \& Dunbar, R. I. M. (1994). Territory size and defendability in primates. Behav. Ecol. Sociobiol. 35: 347-354.

Miquelle, D. G., Smirnov, E. N., Merrill, T. W., Myslenkov, A. E., Quigley, H.B., Hornocker, M. G. \& Schleyer, B. (1999). Hierarchical spatial analysis of Amur tiger relationships to habitat and prey. In Riding the tiger: Tiger conservation in humandominated landscapes: 71-99. Seidensticker, J., Christie, S. \& Jackson, P. (Eds). Cambridge: Cambridge University Press.

Yudakov, A. G. \& Nikolaev, I. G. (1987). Ecology of the Amur tiger: winter observations during 1970-1973 in the western section of central Sikhote-Alin. Moscow: Nauka. [In Russian]. 
